\title{
Regulation of CTP:Phosphocholine Cytidylyltransferase by Cytosolic Lipids in Rat Type II Pneumocytes during Development
}

\author{
LUC J. I. ZIMMERMANN, WEN-SU LEE, AND MARTIN POST \\ The Medical Research Council Group in Lung Development, Neonatal Research Division, \\ Hospital for Sick Children, University of Toronto, Toronto, Ontario, Canada [L.J.I.Z., W.-S.L., M.P.], \\ and Division of Neonatology, Department of Pediatrics, Sophia Children's Hospital, \\ Erasmus University of Rotterdam, Rotterdam, The Netherlands [L.J.I.Z.]
}

\begin{abstract}
CTP:phosphocholine cytidylyltransferase (CT) catalyses a rate regulatory step in the de novo synthesis of surfactant phosphatidylcholine (PC). We have previously shown that CT activity increases during late gestation in alveolar type II cells, and that this increase is most pronounced in microsomes. As it is known that $\mathrm{CT}$ is activated by lipids, we investigated the lipid activation of CT in fetal type II cells during late gestation. The degree of activation of cytosolic CT by PC/oleic acid (OA) (1:1 molar ratio) vesicles was gestation-dependent (a 3-fold stimulation on $\mathrm{d}$ 18 and a 1.5 -fold stimulation on $\mathrm{d} 21$ ). In contrast, microsomal CT activation by PC/OA vesicles (1.5-fold) remained constant with advancing gestation. Lipids extracted from microsomes of fetal type II cells of different gestational ages (d 18-21) did not differ in their ability to activate either cytosolic CT of d 18 or 21 fetal type II cells, purified CT from adult lung, or delipidated purified CT. In contrast, lipids extracted from cytosol of fetal type II cells of different gestational ages (d 18 and 21) differed in
\end{abstract}

their ability to activate either delipidated cytosolic CT of fetal type II cells, or delipidated purified CT from adult lung. Day 21 cytosolic lipids activated CT more than d 18 cytosolic lipids. Both cytosolic and purified CT, when delipidated by acetone/ butanol extraction, showed reduced activities. Several lipids were tested for their ability to activate cytosolic CT. Acidic phospholipids and the mixture of PC/OA (1:1) were the strongest stimulators of cytosolic CT activity. We conclude that cytosolic but not microsomal lipids are involved in the developmental activation of cytosolic CT in fetal type II cells at late gestation. (Pediatr Res 38: 864-869, 1995)
Abbreviations
CT, CTP:phosphocholine cytidylyltransferase
PC, phosphatidylcholine
$\mathbf{O A}$, oleic acid

The production of pulmonary surfactant, which is produced by the alveolar type II cells, is initiated during the latter part of gestation. The subsequent accumulation of surfactant in the airways coincides with the ability of the newborn to establish regular air breathing. Surfactant deficiency due to lung immaturity is the main factor responsible for the occurred of respiratory distress syndrome in premature neonates. $\mathrm{PC}$ is a major component of surfactant $(1,2)$. CT (EC. 2.7.7.15) has been demonstrated to catalyze a rate-limiting step in the de novo synthesis of PC in the developing lung $(3,4)$. We have previously shown that CT activity increases in fetal type II cells at late gestation (5). The increase in enzyme activity coincides with an increase in PC synthesis (5). The developmental regulation of $\mathrm{CT}$ in fetal type II cells remains to be

Received December 20, 1994; accepted June 27, 1995.

Manuscript dedicated to Professor H.K.A. Visser in honor of his retirement.

Correspondence: Dr. M. Post, Division of Neonatology, Hospital for Sick Children, 555 University Ave., Toronto, Ontario M5G 1X8, Canada.

Supported by a group grant from the Medical Research Council of Canada. elucidated. Recently, we have reported that the increased PC synthesis by fetal type II cells at late gestation is due in part to an increase in CT protein (6). However, there is overwhelming evidence that CT may also be regulated by enzyme-membrane interactions (for reviews, see Refs. 7 and 8). The enzyme exists in an inactive soluble form and an active membrane-bound form $(9,10)$. Recent studies have identified the lipid-binding domain of $\mathrm{CT}$ as an $\alpha$-helical domain of the protein $(11,12)$. Our previous studies with fetal type II cells demonstrated that CT protein content and activity increased in the microsomal fraction with advancing gestation with no developmental change in the cytosolic fraction $(5,6)$. In whole fetal lung, fatty acids $(13-15)$ and phospholipids $(16,17)$ may play an important physiologic role in the activation of CT during development, possibly through CT-membrane interactions (13). However, results from studies with whole lung cannot be directly extrapolated to developmental changes in type II cells, the producers of surfactant, as pointed out in several reviews (2, $18,19)$. In the present study, therefore, we investigated CT 
activation by microsomal and cytosolic lipids of maturing type II pneumocytes. An abstract of these studies has been published previously (20).

\section{METHODS}

Materials. Female (200-250 g) and male (250-300 g) Wistar rats were purchased from Charles River (St. Constant, Quebec) and bred in our animal facilities. Cell culture media, antibiotics, and trypsin were obtained from GIBCO Canada (Burlington, Ontario). FCS was from Flow Laboratories (McLean, VA), collagenase and DNAse from Worthington Biochemical (Freehold, NJ). Cell culture flasks were purchased from Falcon (Becton Dickinson, Lincoln Park, NJ). [Methyl$\left.{ }^{14} \mathrm{C}\right]$ phosphocholine and $\left[\right.$ methyl $\left.-{ }^{14} \mathrm{C}\right] \mathrm{CDP}$ choline were from New England Nuclear Research (Dupont Canada, Mississauga, Ontario). All remaining unlabeled biochemicals were obtained from Sigma Chemical Co. (St. Louis, MO).

Cell cultures. Timed pregnant rats were killed by diethylether excess on $d 18-21$ of gestation (term $=d 22$ ), and the fetuses were aseptically removed from the dams. The epithelial cells were isolated from the fetal lungs as described in detail elsewhere (21-23). Although the term "type II cells" is used in this report, the cuboidal epithelium which lines the acinar tubules during the late pseudo-glandular and early canalicular stages of lung development does not contain lamellar bodies, the phenotypic marker for type II cells. In previous studies, we have shown that these cells do express other phenotypic features of type II cells and possess antigenic determinants of mature type II cells $(22,24)$.

Cell fractionation. After overnight incubation in tissue culture flasks, attached cells were collected by scraping in homog-

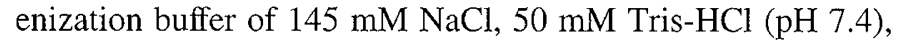
$50 \mathrm{mM} \mathrm{NaF}$, and $2.5 \mathrm{mM}$ EDTA (hereafter referred to as Tris-saline). Postmitochondrial supernatant and microsomal and cytosolic fractions were obtained as previously described (5) and stored at $-70^{\circ} \mathrm{C}$ until processed further.

Enzyme assay. CT activity was assayed in the forward direction by measuring the rate of incorporation of [methyl$\left.{ }^{14} \mathrm{C}\right]$ phosphocholine into CDPcholine as previously described $(5,21)$.

Purification of $\boldsymbol{C T}$. Rats were killed by diethylether excess, and immediately afterward a tracheostomy was performed and lungs were inflated with a pressure of $15 \mathrm{~cm} \mathrm{H}_{2} \mathrm{O}$. The thorax was opened, and the lungs were thoroughly perfused with normal saline via injection in the right ventricle and opening the left atrium. Lungs were immediately frozen in liquid nitrogen and kept at $-70^{\circ} \mathrm{C}$ until the purification was started. CT was purified from $100 \mathrm{~g}$ of lung as described by Weinhold et al. for liver (25). A 2278-fold purification was obtained and a yield of $9.34 \%$ of total cytosolic activity (21).

Delipidation of purified CT and cytosol. Purified CT and cytosolic CT were delipidated by acetone/butanol extraction according to the method of Fiscus and Schneider (26) as modified by Chu and Rooney (17). The final pellet was resuspended in Tris-saline (see above) by sonication for $2 \times 20 \mathrm{~s}$ at $0^{\circ} \mathrm{C}$, and foam was removed under vacuum.
Lipid extraction and preparation of (phospho)lipid vesicles. Total lipids were extracted from cell fractions with chloroform/methanol by the method of Bligh and Dyer (27). Phospholipid phosphorus was measured according to Bartlett (28). All microsomal and cytosolic lipid concentrations are therefore given as micromolar lipid phosphorus. Lipids to be tested were dried under a stream of $\mathrm{N}_{2}$ at $40^{\circ} \mathrm{C}$. After traces of solvent were removed under high vacuum, lipids were resuspended in Trissaline (see above) by sonication (29) for three times at $30 \mathrm{~s}$ each, or longer when the turbid suspension had not clarified.

Protein measurements. Protein concentrations were determined by the method of Bradford (30), using BSA as the standard.

Statistical analysis. Statistical differences between various groups were analyzed by paired or unpaired $t$ test (for two groups) or by analysis of variance with the Neumann-Keuls test (for more than two groups). Statistical significance was accepted at the $p<0.05$ level (two-tailed).

\section{RESULTS}

Stimulation of CT activity of fetal type II cells by phospholipid vesicles. We first investigated whether activation of CT activity in cytosol and microsomes by phospholipids varied as a function of development. As PC/OA (1:1 molar ratio) vesicles at a (combined) concentration of $0.5 \mathrm{mM}$ (PC and OA each $0.25 \mathrm{mM}$ ) have been shown to stimulate CT activity maximally (29), we assayed CT activity in both cell fractions in the absence and presence of $0.5 \mathrm{mM}$ PC/OA (1:1) vesicles. The CT activities in cytosol and microsomes measured in the absence of PC/OA were in the same range as published previously (5). Independent of gestational age, CT activity in the microsomal fraction of fetal type II cells was stimulated approximately 1.5 -fold by $\mathrm{PC} / \mathrm{OA}$ vesicles (Fig. 1). In contrast, activation of cytosolic CT by PC/OA vesicles was gestation-

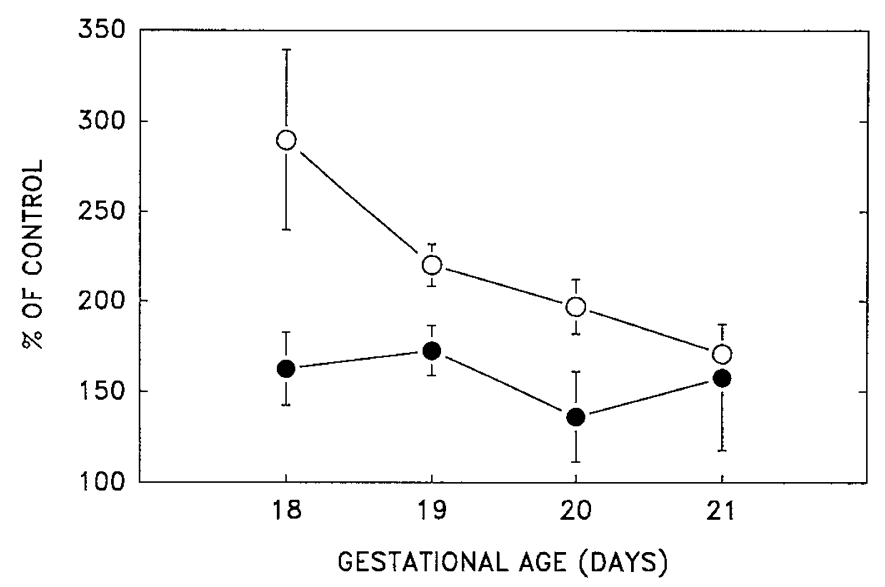

Figure 1. Gestation-dependent activation of cytidylyltransferase in subcellular fractions by $\mathrm{PC} / \mathrm{OA}$ vesicles. Cytosolic (O) and microsomal (O) fractions were prepared from type II cells in primary culture, isolated from fetal rats at $18-21 \mathrm{~d}$ of gestation. CT activity was assayed in both fractions in the absence (control) and presence of $0.5 \mathrm{mM}$ PC/OA vesicles $(1: 1 \mathrm{M}$ ratio, $0.25 \mathrm{mM}$ each), which are known to activate the enzyme. Data are presented as percentage of control (activity in the presence of $\mathrm{PC} / \mathrm{OA} \times 100$ /activity in the absence of $\mathrm{PC} / \mathrm{OA}$ ). Each data point represents mean $\pm \mathrm{SE}$ of at least four separate experiments, performed in duplicate. 
dependent. It was activated 3-fold on d 18 but 1.5 -fold on d 21 (Fig. 1). The greater lipid stimulation of cytosolic CT activity in $\mathrm{d} 18$ compared with that of $\mathrm{d} 21$ fetal type II cells suggests that fetal type II cell cytosol contains a higher proportion of inactive $\mathrm{CT}$ at $18 \mathrm{~d}$ than at $21 \mathrm{~d}$ of gestation.

Activation of CT by microsomal lipids of maturing type II cells. We then determined whether microsomal lipids of maturing type II cells differed in their ability to activate CT. Microsomal lipids of d 18 and d 21 fetal type II cells were extracted and their effect on cytosolic CT activity of d 18 and 21 fetal type II cells was assessed. In addition, this effect was compared with those of microsomal lipids from whole adult lung and PC/OA (1:1) vesicles. Figure 2 shows that $d 18$ and 21 microsomal lipids stimulated the cytosolic CT activity in a concentration-dependent manner and to a similar degree as PC/OA vesicles. Stimulation of cytosolic CT activity by microsomal lipids of adult lung was less pronounced than the stimulation by microsomal lipids of fetal type II cells. Day 18 and 21 cytosolic CT activities were different when assayed without lipids $(0.29$ versus $0.56 \mathrm{nmol} / \mathrm{min} / \mathrm{mg}$ of protein) but CT activity in both cytosols was stimulated maximally to the same value (1.82 and $1.86 \mathrm{nmol} / \mathrm{min} / \mathrm{mg}$ of protein) by $100 \mu \mathrm{M}$ lipids (assayed by phospholipid phosphorus) of either d 18 or 21 fetal type II cell microsomes. The amount of microsomal lipids of type II cells increased slightly from d $18(0.016 \mu \mathrm{g}$ of phosphorus $/ \mu \mathrm{g}$ of protein) to $\mathrm{d} 21(0.020 \mu \mathrm{g}$ of phosphorus $/ \mu \mathrm{g}$ of protein). Thus although the amount of microsomal lipids increases during development, there is no qualitative developmental difference in the ability of these microsomal lipids to activate CT in fetal type II cells. This was confirmed by testing the ability of $50 \mu \mathrm{M}$ microsomal lipids of fetal type II cells of 18-21 d gestation to stimulate purified lung CT (Table 1). Microsomal lipids from d 18 to 21 fetal type II cells stimulated CT activity. However, no significant gestation-dependent differences in CT activation were observed. Because the presence of residual lipids may mask the effect of the microsomal lipids on purified CT, we delipidated purified CT by acetone/butanol

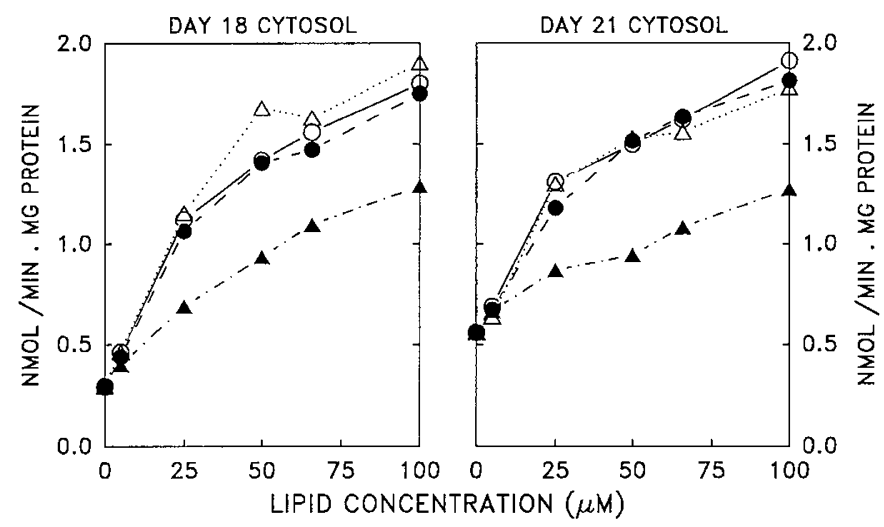

Figure 2. Activation of cytosolic cytidylyltransferase by microsomal lipids. $\mathrm{CT}$ activity was assayed in $\mathrm{d} 18$ (left) and $\mathrm{d} 21$ (right) cytosol in the presence of different concentrations of PC/OA $(1: 1 \mathrm{M}$ ratio) vesicles $(\triangle)$ (expressed as sum of $[\mathrm{PC}]+[\mathrm{OA}])$ or in the presence of different concentrations of lipids (expressed as $\mu \mathrm{M}$ of lipid phosphorus) extracted from microsomes of $\mathrm{d} 18 \mathrm{fetal}$ type II cells $(\bigcirc)$, d 21 fetal type II cells $(\boldsymbol{O})$ or adult whole lung $(\boldsymbol{\Delta})$. Assays were performed in duplicate. The experiment was repeated with almost identical results.
Table 1. Activation of purified lung cytodylyltransferase by microsomal and cytosolic lipids

\begin{tabular}{|c|c|c|}
\hline \multirow[b]{2}{*}{ Addition } & \multicolumn{2}{|c|}{ Cytidylyltransferase activity } \\
\hline & Purified CT & Delipidated purified CT \\
\hline No lipids added & $1310 \pm 127 \dagger(1) \ddagger$ & $46 \pm 14$ \\
\hline $\mathrm{PC} / \mathrm{OA}(1: 1 \mathrm{M})$ & $3184 \pm 275$ & $817 \pm 308(17.78)$ \\
\hline \multicolumn{3}{|l|}{ Microsomal lipids } \\
\hline d 18 & $2368 \pm 131 \quad(1.80)$ & $268 \pm 70 \quad(5.82)$ \\
\hline d 19 & $2397 \pm 197(1.83)$ & \\
\hline d 20 & $2083 \pm 118$ & \\
\hline d 21 & $1900 \pm 223(1.45)$ & $234 \pm 38 \quad(5.09)$ \\
\hline \multicolumn{3}{|l|}{ Cytosolic lipids } \\
\hline d 18 & $3013 \pm 26 \quad(2.30)$ & $386 \pm 75(8.39)^{*}$ \\
\hline d 19 & $3263 \pm 157$ (2.49) & \\
\hline d 20 & $3236 \pm 170 \quad(2.47)$ & \\
\hline d 21 & $3275 \pm 13 \quad(2.50)$ & $682 \pm 172(14.82)^{*}$ \\
\hline
\end{tabular}

CT was purified from whole adult lung, and the activation of $\mathrm{CT}$ was studied in the presence of $50 \mu \mathrm{M}$ mixed PC/OA (1:1 M ratio, $25 \mu \mathrm{M}$ each) vesicles or lipids (50 $\mu \mathrm{M}$ lipid phosphorus) extracted from microsomes or cytosol from type II cells isolated from different days of gestation. In separate experiments, $\mathrm{CT}$ was first delipidated by acetone/butanol extraction before studying lipid activation (protein recovery during extraction was $60 \%$ ). The CT activities are expressed $\mathrm{nmol} / \mathrm{min} / \mathrm{mg}$ of protein (and fold change compared to controls without the addition of lipids). mean \pm SD are shown for four separate experiments.

* Significantly different $(p<0.02)$ by $t$ test.

$\dagger$ Values are $\mathrm{nmol} / \mathrm{min} / \mathrm{mg}$ of protein.

$\$$ Figures in parentheses are fold increase.

extraction. The extraction drastically reduced the $\mathrm{CT}$ activity (1310 $\mathrm{nmol} / \mathrm{min} / \mathrm{mg}$ of protein to $46 \mathrm{nmol} / \mathrm{min} / \mathrm{mg}$ of protein measured with $25 \mu \mathrm{L}$ of the purified enzyme solution). The activity of the delipidated $\mathrm{CT}$ was partially restored by the addition of $50 \mu \mathrm{M}$ PC/OA $(1: 1,25 \mu \mathrm{M}$ each) vesicles $(817$ $\mathrm{nmol} / \mathrm{min} / \mathrm{mg}$ of protein), but not to the same level as the unextracted purified CT activated by $50 \mu \mathrm{M}$ PC/OA $(1: 1)$ vesicles (3184 $\mathrm{nmol} / \mathrm{min} / \mathrm{mg}$ of protein). Microsomal lipids (50 $\mu \mathrm{M}$ lipid phosphorus) of fetal type II cells also increased the activity of the delipidated enzyme but less than the PC/OA vesicles (Table 1). Again, there was no difference in the ability of d 18 and 21 microsomal lipids of fetal type II cells to stimulate delipidated purified CT (Table 1).

Activation of $\mathrm{CT}$ by cytosolic lipids of maturing type II cells. As previous studies with whole fetal lung have suggested that cytosolic CT can be activated by cytosolic lipids $(16,17)$, we also examined the effect of cytosolic lipid extracts of fetal type II cells on CT activation. In preliminary experiments it was found that the activation of $\mathrm{CT}$ in delipidated cytosol by cytosolic lipids was concentration-dependent. Saturation (maximal stimulation) of CT activity was obtained with 5 times the amount of lipids present in the original cytosol (approximately $95 \mu \mathrm{M}$ lipid phosphorus) (not shown). Using the same saturating conditions, we then compared the ability of cytosolic lipids from d 18 and 21 fetal type II cells to stimulate delipidated cytosolic CT of d 18 and 21 fetal type II cells (Fig. 3). Delipidation of cytosol of d 18 and 21 fetal type II cells resulted in a drastic reduction of $\mathrm{CT}$ activity. The $\mathrm{CT}$ activities of both d 18 and 21 delipidated cytosol were restored on readdition of cytosolic lipids (approximately $0.5 \mathrm{nmol} / \mathrm{min} / \mathrm{mg}$ of protein). However, this activity is still lower than that of unextracted cytosolic CT activated by lipids (approximately 


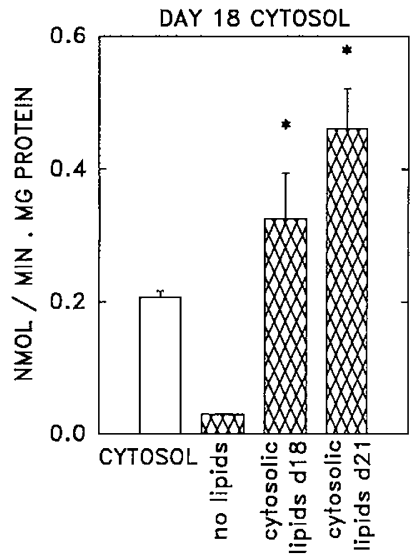

DELIPIDATED CYTOSOL

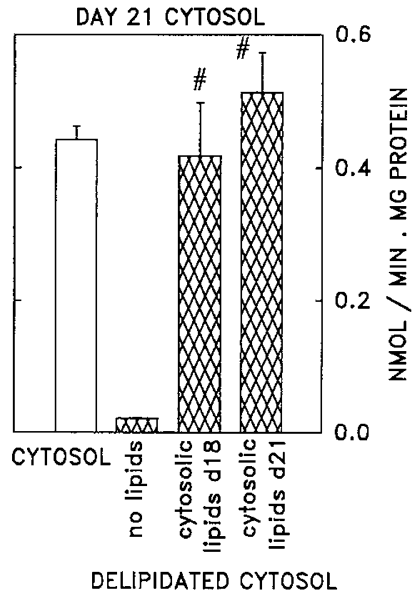

Figure 3. Activation of delipidated cytosolic cytidylyltransferase by cytosolic lipids from $\mathrm{d} 18$ and 21 fetal type II cells. CT activity was assayed in normal cytosol (open bars) or in cytosol delipidated by acetone/butanol (cross-hatched bars) of $\mathrm{d} 18$ (graph on the left) and d 21 (graph on the right) fetal type II cells. $\mathrm{CT}$ activity in delipidated cytosols was assayed in the absence and presence of cytosolic lipids from d 18 and 21 fetal type II cells. The amount of lipids added to the delipidated cytosol was 5 times the amount of lipid present in the original cytosol (the average final concentration in the assay was $96 \mu \mathrm{M}$ for $\mathrm{d}$ 18 cytosolic lipids and $92.4 \mu \mathrm{M}$ for d 21 cytosolic lipids). Data are presented as mean $\pm \mathrm{SE}$ of four separate experiments, all performed in duplicate. Comparison between the activities in the presence of either $\mathrm{d} 18$ or 21 cytosolic lipids by paired $t$ test (two-sided): $* p=0.075(n=4$, all in duplicate) and $\# p=0.064(n=4$, all in duplicate); all eight comparisons (d 18 and $21 \mathrm{CT}$ data) taken together $p=0.019(n=8$, all in duplicate).

$1.85 \mathrm{nmol} / \mathrm{min} / \mathrm{mg}$ of protein). It appeared that cytosolic lipids of d 21 had a greater stimulatory effect on CT activity than d 18 cytosolic lipids [significantly different when all eight comparisons ( 18 and 21 enzyme data) were taken together $(n=$ $8), p=0.019$ by paired $t$ test]. As these measurements were performed under saturating conditions of lipids, these data suggest that there is a difference in cytosolic lipid composition between d 18 and 21 cytosol of fetal type II cells. To confirm these cytosolic findings, we tested the ability of cytosolic lipids (50 $\mu \mathrm{M}$ lipid phosphorus) to activate purified CT delipidated by acetone/butanol extraction (Table 1). Day 21 cytosolic lipids activated delipidated CT to a significantly greater extent than did d 18 cytosolic lipids. When the same experiment was carried out with nondelipidated purified $\mathrm{CT}$, no significant gestation-dependent differences were observed (Table 1), likely because the effect is masked by the presence of residual lipids in the purified CT preparation.

Comparison of activation of cytosolic CT by various lipids. Cytosolic lipids, microsomal lipids, or combinations of both (all from d 20 fetal type II cells), stimulated CT activity of delipidated d 20 cytosol $(0.04 \mathrm{nmol} / \mathrm{min} / \mathrm{mg}$ of protein) to the same level as $0.5 \mathrm{mM}$ PC/OA (1:1, each $0.25 \mathrm{mM})$ vesicles $(1.27 \mathrm{nmol} / \mathrm{min} / \mathrm{mg}$ of protein) when saturating conditions of lipids were used. However, CT in delipidated cytosol could not be activated to the level found in cytosol before acetone/ butanol extraction $(2.42 \mathrm{nmol} / \mathrm{min} / \mathrm{mg}$ of protein in the presence of $0.5 \mathrm{mM} \mathrm{PC} / \mathrm{OA}$ vesicles). To further investigate which lipid(s) may be responsible for the activation of cytosolic CT, we investigated the effect of two phospholipids, $\mathrm{PC}$ and phosphatidylglycerol, and OA on cytosolic CT activity. Figure 4

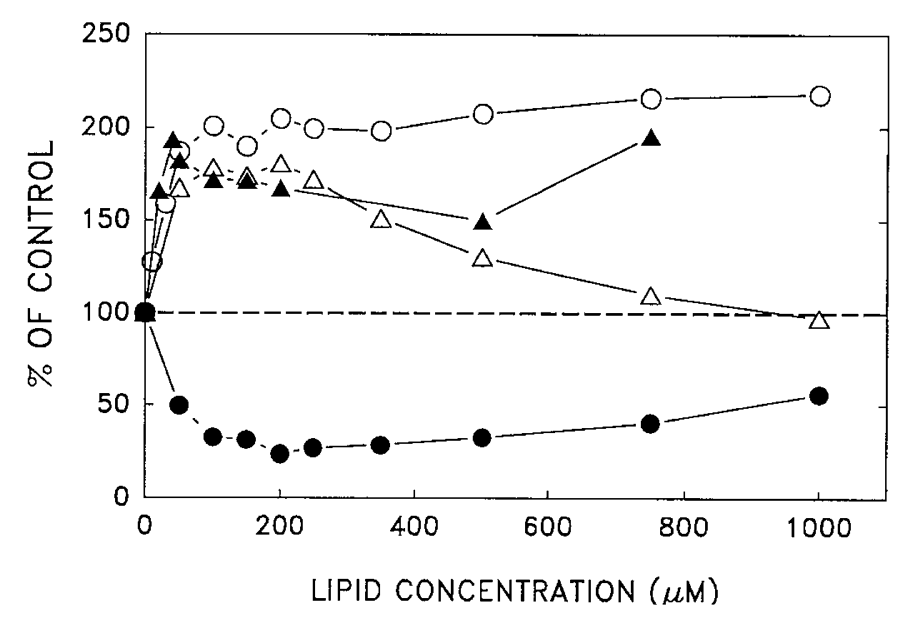

Figure 4. Effect of different lipids on cytosolic cytidylyltransferase activity. CT activity was assayed in cytosol prepared from d 20 fetal type II cells in the absence (control) or presence of different concentrations of vesicles consisting of PC $(\bullet)$, OA $(\triangle)$, phosphatidylglycerol $(\boldsymbol{\Delta})$, or mixed PC/OA vesicles $(1: 1$ $\mathrm{M}$ ratio) $(\mathrm{O})$ (concentration expressed as the sum of $[\mathrm{PC}]+[\mathrm{OA}]$ ). Values are expressed as percentage of control $(0.35 \mathrm{nmol} / \mathrm{min} / \mathrm{mg}$ of protein). Assays were performed in duplicate. The experiment was repeated with almost identical results.

shows that the stimulatory effect of PC/OA (1:1) vesicles on cytosolic CT activity was dependent on concentration up to 50 $\mu \mathrm{M}(25 \mu \mathrm{M}$ each of $\mathrm{PC}$ and $\mathrm{OA})$ when maximum stimulation was reached. Stimulation of CT with PC/OA (1:1) vesicles was noted up to at least $1 \mathrm{mM}$. A similar concentration versus $\mathrm{CT}$ activity curve was obtained with phosphatidylglycerol vesicles. OA alone stimulated CT activity at low $(<100 \mu \mathrm{M})$ but not at high concentrations $(>200 \mu \mathrm{M})$. PC vesicles alone inhibited cytosolic CT activity. Based upon these results a variety of other lipids were tested at a concentration of $50 \mu \mathrm{M}$ for their ability to activate cytosolic CT from d 20 fetal type II cells (not shown). Consistent with previous studies with CT obtained from other sources (29, 31-33), vesicles of acidic phospholipids, phosphatidylglycerol (6.44 \pm 0.08 -fold stimulation), phosphatidylinositol (5.01 \pm 0.15 -fold), and phosphatidylserine $(4.04 \pm 0.02$-fold) were the strongest stimulators of cytosolic CT activity in fetal type II cells. Phosphatidic acid (2.29 \pm 0.01 -fold stimulation), phosphatidylethanolamine (2.92 \pm $0.24)$, and 1,2-dioctanoylglycerol vesicles (3.04 \pm 0.02$)$ stimulated CT activity to some extent. Independent of fatty acid chain, PC vesicles did not stimulate CT activity. Addition of 1,3-diolein and 1-oleyl-2-acetylglycerol vesicles also did not activate CT. Oleic acid ( $5.13 \pm 0.34$-fold) but not palmitic acid vesicles ( $1.38 \pm 0.05$-fold) stimulated $\mathrm{CT}$ activity to the same maximal value as the acidic phospholipids. The effect of most stimulatory lipids was less when experiments were repeated at a concentration of $500 \mu \mathrm{M}$ (not shown).

\section{DISCUSSION}

Several mechanisms by which the activity of CT is regulated, and which are probably interrelated, have been studied in the fetal lung, including subcellular translocation of the enzyme from cytosol to microsomes (13), activation by fatty acids $(13,14)$ and phospholipids $(16,17,31,34)$, and regulation by phosphorylation/dephosphorylation (35). Although ac- 
tivation of cytosolic CT by lipids has been shown in a number of these studies, the role of this mechanism in activating CT in maturing type II cells has not been determined. In the present study, we found that the developmental increase in CT activity in fetal rat type II cells during late gestation (5) was in part mediated by an increased capacity of cytosolic lipids to activate $\mathrm{CT}$ with advancing gestation. Microsomal lipids also stimulated CT activity, but no developmental difference was demonstrated. In previous studies with whole lung it has been shown that activation of cytosolic CT by either estrogen (17) or betamethasone (36) is lipid-dependent. Mallampalli et al. (36) demonstrated that the administration of betamethasone to pregnant rats increased CT activity in fetal rat lungs by increasing the proportion of cytosolic CT in the $\mathrm{H}$-form. These hormonal findings cannot directly be extrapolated to CT activation during normal lung development. However, Chu et al. (16) have found that lipids also regulate cytosolic CT activity during whole rabbit lung development. Our present findings with isolated maturing type II cells of fetal rat lungs are in agreement with a developmental regulation of CT by cytosolic lipids. In addition, we showed the developmental activation of purified rat lung CT by cytosolic lipids of fetal type II cells. It was somewhat surprising that no developmental difference was found in the ability of microsomal lipids to activate CT because we have previously observed that the specific and total activity of CT increased more in the microsomal fraction with advancing gestation than in the cytosolic fraction (5). This may be explained by two mechanisms, which may be complementary. It is possible that a developmental change in the cytosolic lipids promotes the translocation of CT from cytosol to microsomes, which are also more abundant at a later gestational age (37) and contain an increased amount of phospholipid fatty acids (38). A likely lipid candidate is FFA. Fatty acid synthesis increases at late gestation $(39,40)$, and translocation of CT to microsomes by FFA has been demonstrated in whole lung (13). Another possibility is that newly synthesized CT remains associated with the microsomal membranes, thereby increasing microsomal CT activity with advancing gestation (6), whereas cytosolic CT activity remains a less active pool, which is regulated by cytosolic lipids. Our present data are compatible with developmental activation of preexisting CT enzyme as opposed to increased enzyme synthesis during late gestation. We have previously reported, however, that CT mRNA and protein levels increased in fetal type II cells with advancing gestation (6). Increased CT activity in fetal type II cells stimulated with conditioned medium from cortisol-treated fetal lung fibroblasts (41) also appears in part to be regulated at a pretranslational level (42). Therefore, both mechanisms of increased synthesis and activation may be important and complement each other during type II cell development.

In the present study, activities of both CT in fetal type II cell cytosol and purified lung CT were significantly reduced when lipids were removed. CT activity was partially restored by readdition of lipids, confirming the lipid dependency of CT activity. However, readdition of lipids to the delipidated cytosolic or purified CT was unable to activate CT to the same level as unextracted CT activated by lipids. The reason for this finding is not known, but it is possible that the extraction of lipids had a damaging effect on $\mathrm{CT}$ or that nonlipid factors necessary for optimal CT activity are lost during the extraction. With regard to the question of which lipids are able to activate cytidylyltransferase in fetal type II cell cytosol, we demonstrated that vesicles of anionic phospholipids, oleic acid alone, or mixed egg PC/OA (1:1 molar ratio) vesicles stimulated CT activity. This is consistent with studies using whole fetal lung cytosol $(29,31)$ and purified rat liver cytidylyltransferase $(32$, 33). OA was enough to provide the required negative charge for activation of cytosolic CT. It is likely that OA incorporated in lipids present in the cytosol, thereby forming anionic membranes which bound and stimulated CT activity $(29,32)$. We did not investigate the lipid composition of the type II cell cytosol and therefore are, at this moment, unable to answer the question of which lipid is physiologically important during type II cell development. Chu et al. determined the lipid composition of whole fetal lung cytosol during development (16) and after estrogen stimulation (17), but were unable to identify any individual lipid component that could explain the activation of CT. Mallampalli et al.'s $(15,36)$ studies suggest that phosphatidylglycerol and unsaturated fatty acids play an important role in cytosolic CT activation by the conversion of the L-form to the $\mathrm{H}$-form either in vitro (15) or after betamethasone stimulation in vivo (36). The physiologic importance of these findings during normal development however remain to be established. In the present study we found that cytosolic CT activity of fetal type II cells was inhibited by PC vesicles. This may be due to a feedback inhibition of the end product of the pathway, PC, on the rate limiting enzyme, CT, as was suggested by Jamil et al. $(43,44)$ using rat hepatocytes.

In conclusion, cytosolic lipids play an important role in the developmental activation of $\mathrm{CT}$ in fetal rat type II cells during late gestation, but the precise mechanism of activation remains to be elucidated.

\section{REFERENCES}

1. Goerke J 1974 Lung surfactant. Biochim Biophys Acta 344:241-261

2. Post M, Van Golde LMG 1988 Metabolic and developmental aspects of pulmonary surfactant systems. Biochim Biophys Acta 947:249-286

3. Tokmakjian S, Possmayer F 1981 Pool sizes of the precursors for phosphatidylcholine synthesis in developing rat lung. Biochim Biophys Acta 666:176-180

4. Post M, Batenburg JJ, Van Golde LMG, Smith BT 1984 The rate-limiting reaction in phosphatidylcholine synthesis by alveolar type II cells isolated from fetal lung. Biochim Biophys Acta 795:558-563

5. Zimmermann LJ, Hogan M, Carlson KS, Smith BT, Post M 1993 Regulation of phosphatidylcholine synthesis in fetal type II cells by CTP:phosphocholine cytidylyltransferase. Am J Physiol 264:L575-L580

6. Hogan M, Zimmermann LJ, Wang J, Kuliszewski M, Liu J, Post M 1994 Increased expression of CTP:phosphocholine cytidylyltransferase in maturing type II cells. Am J Physiol 267:L25-L32

7. Vance DE, Pelech SL 1984 Enzyme translocation in the regulation of phosphatidylcholine biosynthesis. Trends Biochem Sci 9:17-20

8. Tronchere H, Record M, Terce F, Chap H 1994 Phosphatidylcholine cycle and regulation of phosphatidylcholine biosynthesis by enzyme translocation. Biochim Biophys Acta 1212:137-151

9. Feldman DA, Rounsifer ME, Charles L, Weinhold PA 1990 CTP:phosphocholine cytidylyltransferase in rat lung: relationship between cytosolic and membrane forms. Biochim Biophys Acta 1045:49-57

10. Weinhold PA, Rounsifer ME, Charles L, Feldman DA 1989 Characterization of cytosolic forms of CTP:choline-phosphate cytidylyltransferase in lung, isolated alveolar type II cells, A549 cell and Hep G2 cells. Biochim Biophys Acta 1006:299-310

11. Wieder T, Geilen CC, Wieprecht M, Becker A, Orfanos CE 1994 Identification of a putative membrane-interacting domain of CTP:phosphocholine cytidylyltransferase from rat liver. FEBS Lett 345:207-210

12. Johnson JE, Cornell RB 1994 Membrane-binding amphipathic alpha-helical peptide derived from CTP:phosphocholine cytidylyltransferase. Biochemistry 33:4327--4335

13. Weinhold PA, Rounsifer ME, Williams SE, Brubaker PG, Feldman DA 1984 CTP:phosphorylcholine cytidylyltransferase in rat lung. The effect of free fatty acids 
on the translocation of activity between microsomes and cytosol. J Biol Chem 259:10315-10321

14. Xu ZX, Smart DA, Rooney SA 1990 Glucocorticoid induction of fatty-acid synthase mediates the stimulatory effect of the hormone on choline-phosphate cytidylyltransferase activity in fetal rat lung. Biochim Biophys Acta 1044:70-76

15. Mallampalli RK, Salome RG, Hunninghake GW 1993 Lung CTP:choline-phosphate cytidylyltransferase: activation of cytosolic species by unsaturated fatty acid. Am J Physiol 265:L158-L163

16. Chu AJ, Rooney SA 1985 Developmental differences in activation of cholinephosphate cytidylyltransferase by lipids in rabbit lung cytosol. Biochim Biophys Acta 835:132-140

17. Chu AJ, Rooney SA 1985 Stimulation of cholinephosphate cytidylyltransferase activity by estrogen in fetal rabbit lung is mediated by phospholipids. Biochim Biophys Acta 834:346-356

18. Pelech SL, Vance DE 1984 Regulation of phosphatidylcholine biosynthesis. Biochim Biophys Acta 779:217-251

19. Rooney SA 1985 The surfactant system and lung phospholipid biochemistry. Am Rev Respir Dis 131:439-460

20. Zimmermann L, Post M 1992 Regulation of CTP:phosphocholine cytidylyltransferase by lipids in rat type II pneumocytes during development. Am Rev Respir Dis 145:A872

21. Zimmermann LJ, Lee W-S, Smith BT, Post M 1994 Cyclic AMP-dependent protein kinase does not regulate CTP:phosphocholine cytidylyltransferase activity in maturing type II cells. Biochim Biophys Acta 1211:44-50

22. Caniggia I, Tseu I, Han RNN, Smith BT, Tanswell K, Post M 1991 Spatial and temporal differences in fibroblast behavior in fetal rat lung. Am J Physiol 261:LA24-L433

23. Jassal D, Han RNN, Caniggia I, Post M, Tanswell AK 1991 Growth of distal fetal rat lung epithelial cells in a defined serum-free medium. In Vitro Cell Dev Biol 27A:625-632

24. Post M, Smith BT 1988 Histochemical and immunocytochemical identification of alveolar type II epithelial cells isolated from fetal rat lung. Am Rev Respir Dis 137:525-530

25. Weinhold PA, Rounsifer ME, Feldman DA 1986 The purification and characterization of CTP:phosphorylcholine cytidylyltransferase from rat liver. J Biol Chem 261:5104-5110

26. Fiscus WG, Schneider WC 1966 The role of phospholipids in stimulating phosphorylcholine cytidyltransferase activity. J Biol Chem 241:3324-3330

27. Bligh EG, Dyer WJ 1959 A rapid method of total lipid extraction and purification. Can J Biochem Physiol 37:911-917

28. Bartlett GR 1959 Phosphorus assay in column chromatography. J Biol Chem $234: 466-468$

29. Feldman DA, Rounsifer ME, Weinhold PA 1985 The stimulation and binding of CTP:phosphorylcholine cytidylyltransferase by phosphatidylcholine-oleic acid vesicles. Biochim Biophys Acta 833:429-437

30. Bradford MM $1976 \mathrm{~A}$ rapid and sensitive method for the quantitation of microgram quantities of protein utilizing the principle of protein-dye binding. Anal Biochem $72: 248-254$

31. Feldman DA, Dietrich JW, Weinhold PA 1980 Comparison of the phospholipid requirements and molecular form of CTP:phosphocholine cytidylyltransferase from rat lung, kidney, brain and liver. Biochim Biophys Acta 620:603-611

32. Cornell RB 1991 Regulation of CTP:phosphocholine cytidylyltransferase by lipids. 1 . Negative surface charge dependence for activation. Biochemistry 30:5873-5880

33. Cornell RB 1991 Regulation of CTP:phosphocholine cytidylyltransferase by lipids. 2 Surface curvature, acyl chain length, and lipid-phase dependence for activation. Biochemistry 30:5881-5888

34. Rooney SA, Wai-Lee TS, Gobran L, Motoyama EK 1976 Phospholipid content, composition and biosynthesis during fetal lung development in the rabbit. Biochim Biophys Acta 431:447-458

35. Radika K, Possmayer F 1985 Inhibition of foetal pulmonary choline-phosphate cytidylyltransferase under conditions favouring protein phosphorylation. Biochem $\mathbf{J}$ 232:833-840

36. Mallampalli RK, Walter ME, Peterson MW, Hunninghake GW 1994 Betamethasone activation of CTP:cholinephosphate cytidylyltransferase in vivo is lipid dependent. Am J Respir Cell Mol Biol 10:48-57

37. Carlson KS, Davies P, Smith BT, Post M 1987 Temporal linkage of glycogen and saturated phosphatidylcholine in fetal lung type II cells. Pediatr Res 22:79-82

38. Viscardi RM, McKenna MC 1994 Developmental changes in cholinephosphate cytidylyltransferase activity and microsomal phospholipid fatty acid composition in alveolar type II cells. Life Sci 54:1411-1421

39. Fraslon C, Batenburg JJ 1993 Pre-translational regulation of lipid synthesizing enzymes and surfactant proteins in fetal rat lung in explant culture. FEBS Lett 325:285-290

40. Batenburg JJ, Whitsett JA 1989 Levels of mRNAs coding for lipogenic enzymes in rat lung upon fasting and refeeding and during perinatal development. Biochim Biophys Acta 1006:329-334

41. Post M, Barsoumian A, Smith BT 1986 The cellular mechanism of glucocorticoid acceleration of fetal lung maturation. Fibroblast-pneumonocyte factor stimulates choline-phosphate cytidylyltransferase activity. J Biol Chem 261:2179-2184

42. Batenburg JJ, Elfring RH 1992 Pre-translational regulation by glucocorticoid of fatty acid and phosphatidylcholine synthesis in type II cells from fetal rat lung. FEBS Lett 307:164-168

43. Jamil H, Yao ZM, Vance DE 1990 Feedback regulation of CTP:phosphocholine cytidylyltransferase translocation between cytosol and endoplasmic reticulum by phosphatidylcholine. J Biol Chem 265:4332-4339

44. Jamil H, Vance DE 1990 Head-group specificity for feedback regulation of CTP phosphocholine cytidylyltransferase. Biochem J 270:749-754 